\title{
Unique two-way free-standing thermo- and photo- responsive shape memory azobenzene-containing polyurethane liquid crystal network
}

\author{
Zhi-Bin Wen ${ }^{1,23^{*}}$, Ren-Fan Shao ${ }^{2}$, Jean-Marie Raquez ${ }^{3}$, Noel A. Clark ${ }^{2}$, Ke-Ke Yang ${ }^{1 *}$ and \\ Yu-Zhong Wang ${ }^{1}$
}

\begin{abstract}
In this work, azobenzene-containing polyurethane liquid crystal networks (PULCN(AZO)s) were synthesized using a one-pot strategy to demonstrate excellent two-way free-standing thermo-/photo-responsive shape memory effects. Based on the step-growth nature of hydroxyls and isocyanates, the architectures of the networks were adjusted by controlling the stoichiometries of chemical materials. A uniform monodomain sample was prepared by external stress relaxation via a reversible addition reaction of a dynamic carbamate bond. Two independent transition temperatures assigned to glass transition temperature/melting temperature and liquid crystal phase transition temperature were employed to thermally trigger triple shape memory effects and two-way autonomous actuation. In addition, taking advantage of the trans-cis photoisomerization of azobenzene, the programmed network showed a reversible bending and unbending shape change upon irradiation by visible light at 450 and $550 \mathrm{~nm}$, respectively. Coupling the autonomously thermo-induced contraction/extension actuation and reversible photo-induced bending/unbending behaviors of PULCN(AZO)s in one system will expand their potential applications in emerging multifunctional devices.
\end{abstract}

Keywords: polyurethane network, liquid crystal polymer, reversible actuation, thermo-/photo-induced shape memory effect

\section{INTRODUCTION}

The fascinating anisotropic shape morphing and mechanical properties of liquid crystal polymers (LCPs) have attracted researchers' attention [1-5]. Thermo-responsive LCPs have been widely studied. These materials exhibit thermo-activated contraction or extension along the aligned direction in their order-disorder liquid crystal (LC) phase transition, making them good candidates for shape memory polymers (SMPs). Compared with other SMPs triggered by glass transition temperature $\left(T_{\mathrm{g}}\right)$ or melting temperature $\left(T_{\mathrm{m}}\right)$, the rapid and large-scale reversible actuation of LCPs based on LC phase transition temperature $\left(T_{\mathrm{cl}}\right)$ gives these kinds of materials a range of potential applications, from macro to micro, in actuators, sensors, smart surfaces, and artificial muscles [6-15].

Light is a contactless energy source that can be directed to microscale devices and rapidly turned on or off from spatially remote distances [16]. Apart from thermoresponsive LCPs, photo-responsive LCPs containing azobenzene mesogens have been widely used for fabricating shape-change actuators. Reversible trans-cis photoisomerization causes a tiny decrease in the order parameter of LCPs which contributes to shrinkage in the film surface, resulting in bending and unbending [17-19], twisting [20], oscillations [21], and three-dimensional (3D) movements [22,23]. Considering safety, high-energy UV light is not an ideal source for practical applications. Researchers are keen to design visible/near-infrared (NIR) light-responsive systems [24-27]. Lv et al. [25] developed a robust tubular LCP microactuator to manipulate fluid slugs by its asymmetric topologic variation upon irradiation with intensity gradient visible light, which induces

${ }^{1}$ Collaborative Innovation Center for Eco-Friendly and Fire-Safety Polymeric Materials (MoE), State Key Laboratory of Polymer Materials Engineering, National Engineering Laboratory of Eco-Friendly Polymeric Materials (Sichuan), College of Chemistry, Sichuan University, Chengdu 610064, China

${ }^{2}$ Department of Physics and Soft Materials Research Center, University of Colorado, Boulder, Colorado 80309-0390, USA

${ }^{3}$ Laboratory of Polymeric and Composite Materials Center of Innovation and Research in Materials and Polymers, Materia Nova Research Center \& University of Mons, 23 Place du Parc, B-7000 Mons, Belgium

* Corresponding authors (emails: zhibin_wen@hotmail.com (Wen ZB); kkyangscu@126.com (Yang KK)) 
capillary forces for liquid propulsion. Gelebart et al. [27] described a visible light-responsive azobenzene LC soft actuator that exhibited continuous self-propelling oscillatory motion upon exposure to sunlight. In our previous work [28], a reversible bending and unbending motion of an azo-film was achieved using visible light irradiation.

Free-standing reversible actuation requires macroscopic alignment of mesogens to form a monodomain. A variety of approaches have been applied to form uniform monodomain LCPs, including two-step crosslinking [2931], surface alignment [32-36], microfluidics [11,13], electrospinning process [37], 3D inkjet printing [38-41], and soft lithography $[42,43]$. Despite much success in the implementation of these methods, limited sample size, inability to reprogram, and complex 3D structures remain unique challenges. To overcome these limitations, a new strategy has been developed to generate monodomain LCPs by introducing dynamic covalent bonds. The topological structure of these covalent adaptable networks (CANs) or vitrimers can be reprogrammed via exchange reactions under certain external stimuli [44-46]. These exchangeable chemistries, including transesterification [47-49], transcarbamoyalation [50], boronic-ester bond [51], disulfide [52,53], and allyl sulfide groups [54-56] have been applied to prepare monodomain LCPs. In previous work [50], we fabricated a monodomain LCP by transcarbamoyalation. A single system exhibits two-way reversible strains and multiple shape memory effects (SME) triggered by two independent isotropic-nematic and nematic-smectic phase transitions.

Herein, we report a series of thermo-/photo-responsive shape memory azobenzene-containing polyurethane liquid crystal networks (PULCN(AZO)s) synthesized from AZO-diol (monomer), 1,6-hexamethylene diisocyanate (HDI, extender), and 4-arm polyethylene glycol ( ${ }^{4} \mathrm{PEG}_{4 \mathrm{k}}$, crosslinker) (Fig. 1a). By taking advantage of a large number of exchangeable carbamate bonds, a uniform monodomain LCP was developed at $150^{\circ} \mathrm{C}$ for $30 \mathrm{~min}$, which possesses the excellent thermomechanical freestanding reversible actuation capability (Fig. 1b, d). Moreover, a thermo-induced triple SME (TSME) driven by $T_{\mathrm{g}} / T_{\mathrm{m}}$ and $T_{\mathrm{cl}}$ was explored. Thanks to the trans-cis photoisomerization of azobenzene, a unique photomechanical reversible shape change was achieved by visible light irradiation at 450 and $550 \mathrm{~nm}$ (Fig. 1c, d).

\section{EXPERIMENTAL SECTION}

\section{Chemical materials}

2-amino-6-methoxybenzothiazole, $\quad \mathrm{N}, \mathrm{N}$-dimethylforma-

a Synthesis of azobenzene-containing polyurethane liquid crystal network

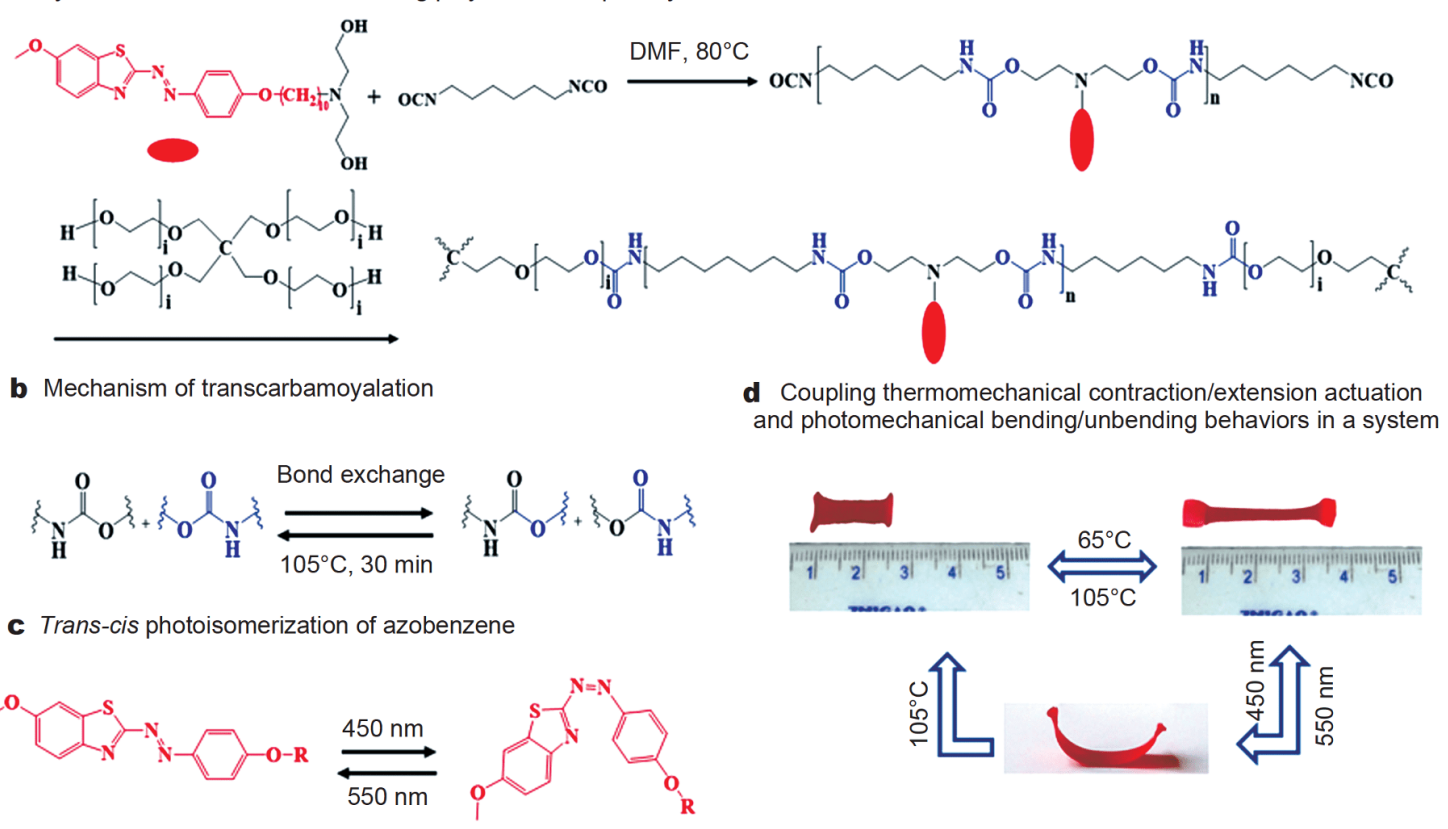

Figure 1 (a) Synthesis of PULCN(AZO)s. Conditions: 1) DMF, $80^{\circ} \mathrm{C}, 3 \mathrm{~h}$, DBTDL as catalyst, with HDI excess; molar ratio: oligomer_1 (1:1.3), oligomer_2 (1:1.5) and oligomer_3 (1:1.7);2) DMF, $80^{\circ} \mathrm{C},{ }^{4} \mathrm{PEG}_{4 \mathrm{k}}$. (b) Mechanism of transcarbamoyalation at $150^{\circ} \mathrm{C}$ for 30 min with a stain of $10 \%$. (c) Trans-cis photoisomerization of azobenzene mesogens. (d) The digital photos show reversible thermomechanical contraction/extension actuation and photomechanical bending/unbending behaviors on a monodomain PULCN(AZO)_1 film. 
mide (DMF) and 1,10-dibromodecane were purchased from Alfa Aesar. HDI, dibutyltindilaurate (DBTDL) and ${ }^{4} \mathrm{PEG}_{4 \mathrm{k}}$ were purchased from Sigma-Aldrich. All other chemicals were supplied by Kelong Reagent Corp. (China) and used as received.

\section{Preparation of PULCN(AZO)s}

The monomer AZO-diol was synthesized referred to our previous work [28]. To prepare a precious LC network, $1 \mathrm{mmol}$ AZO-diol was dissolved in $5 \mathrm{~mL}$ dry DMF at $80^{\circ} \mathrm{C}$ under $\mathrm{N}_{2}$. The stoichiometric chain extender HDI and $1 \mathrm{~mol} \%$ catalyst DBTDL were added. The mixture was kept stirred for $3 \mathrm{~h}$ to form linear oligomer. Then an appropriate amount of crosslinker ${ }^{4} \mathrm{PEG}_{4 \mathrm{k}}$ was added and the solution was placed in a horizontal Teflon dish and kept at $80^{\circ} \mathrm{C}$ under $\mathrm{N}_{2}$ overnight. Finally, the network was obtained after $1 \mathrm{~d}$ in an oven and $2 \mathrm{~d}$ under vacuum at $70^{\circ} \mathrm{C}$.

A control sample (PULCN(AZO)_1_control) was synthesized by the same procedure except that the crosslinker was replaced by pentaerythritol.

\section{Characterization and measurements}

\section{Nuclear magnetic resonance (NMR)}

A Bruker AV400 (Bruker, Switzerland) was used to record the ${ }^{1} \mathrm{H}$ NMR spectra at room temperature, using deuterated chloroform $\left(\mathrm{CDCl}_{3}\right)$ as the solvent, and tetramethyl silane (TMS) as the internal reference.

\section{Gel permeation chromatography (GPC)}

The molecular weight $\left(M_{\mathrm{w}}, M_{\mathrm{n}}\right.$ and polydispersity in$\left.\operatorname{dex} M_{\mathrm{w}} / M_{\mathrm{n}}\right)$ of the oligomers was determined by GPC on a Waters instrument, which is equipped with a Waters model 717 autosampler, a 2414 refractive index detector and a model 1515 pump. Tetrahydrofuran (THF) was used as the eluent at a flow rate of $0.6 \mathrm{~mL} \mathrm{~min}^{-1}$. The column temperature was kept at $40^{\circ} \mathrm{C}$. Polystyrene standard was used for constructing calibration curves.

\section{Dynamic mechanical analysis (DMA)}

Thermomechanical property of the sample was tested on a DMA Q800 (TA Instruments, USA), with a heating rate of $3^{\circ} \mathrm{C} \mathrm{min}^{-1}$ from 0 to $120^{\circ} \mathrm{C}$ with a frequency of $1 \mathrm{~Hz}$.

\section{Differential scanning calorimetry (DSC)}

DSC was recorded on a DSC-Q200 (TA Instrument, USA), over the temperature range of $0-120^{\circ} \mathrm{C}$ with a rate

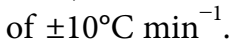

\section{Wide-angle X-ray scattering (WAXS)}

WAXS was performed on a Forvis Technologies X-ray instrument. The source was a $30 \mathrm{~W}$ Genix 3D X-ray generator with $\mathrm{Cu}$ anode (wavelength $\lambda=1.5405 \AA$ and energy $=8.05092 \mathrm{keV}$ ). The detector was a Dectris Eiger $\mathrm{R} 1 \mathrm{M}$ with $0.075 \times 0.075 \mathrm{~mm}^{2}$ pixel size. The film was placed inside an Instec hot stage and measured in transmission mode. AgBe was used as the calibrant, and the sample-to-detector distance was approximately $200 \mathrm{~mm}$. The X-ray scattering patterns were analyzed and plotted in Igor Pro software.

\section{Polarized optical microscopy (POM)}

LC textures of the PULCN(AZO)s were obtained by a Nikon Fil polarizing optical microscope (POM) equipped with a hot stage. In order to determine the LC phase in SME, DMA Q800 with controlled force mode was used to prepare the sample as follows: the film was kept at $105^{\circ} \mathrm{C}$ for $5 \mathrm{~min}$ to isotropy phase. Then it was stretched to $50 \%$ strain, kept at $65^{\circ} \mathrm{C}$ for $30 \mathrm{~min}$ with a rate of $-5^{\circ} \mathrm{C} \mathrm{min}^{-1}$ before releasing force.

The swelling ratio and gel content of PULCN(AZO)s The samples were cut into small pieces, then swollen in chloroform and extracted by chloroform at room temperature for $24 \mathrm{~h}$. The initial mass $\left(m_{0}\right)$ and the dried extracted specimen $\left(m_{1}\right)$ were measured. The gel content $(G(\%))$ was calculated according to the following formula:

$G(\%)=m_{1} / m_{0} \times 100 \%$.

\section{Shape memory properties}

The shape memory experiment was conducted as described previously [28,57], where the experiment was performed on a DMA Q800 (TA Instruments, USA) under controlled force mode. The testing program is available in the Supplementary information.

\section{Photoisomerization properties}

The photo-induced bending-unbending behaviors of the film were studied as follow: first, a monodomain LC film was prepared by transcarbamoyalation on DMA at $150^{\circ} \mathrm{C}$ for $30 \mathrm{~min}$ with a pre-stain of $10 \%$, and then cooled to $25^{\circ} \mathrm{C}$ at $-5^{\circ} \mathrm{C} \min ^{-1}$. Second, the thin film was put on a hot stage (kept at $65^{\circ} \mathrm{C}$ ) and exposed to unpolarized visible light. Light irradiation was performed using Xe lamp (CEL-HXF300 power system, China) through a band-pass filter $(450$ or $550 \mathrm{~nm})$. The intensity was $\sim 20 \mathrm{~mW} \mathrm{~cm}^{-2}$. 


\section{RESULTS AND DISCUSSION}

\section{Preparation of PULCN(AZO)s}

The synthetic route for PULCN(AZO)s is described in Fig. 1. First, an isocyanate-telechelic linear oligomer was prepared by reacting an AZO-monomer with excess HDI. The structure of the oligomer was elucidated by ${ }^{1} \mathrm{H}$ NMR (Fig. S1). Because of the step-growth nature of hydroxyl and isocyanate, the molecular weight of the oligomer enabled control by altering the stoichiometry (molar ratios of $1: 1.3 ; 1: 1.5 ; 1: 1.7$ for Oligomer_1, Oligomer_2 and Oligomer_3), resulting in $M_{\mathrm{n}}$ values of 6200,4200 , and $3400 \mathrm{~g} \mathrm{~mol}^{-1}$, respectively (all data are listed in Table S1). The crosslinker ${ }^{4} \mathrm{PEG}_{4 \mathrm{k}}$ with the weight proportion of $20 \%, 31 \%$ and $40 \%$ were then added in Oligomer_1, Oligomer_2 and Oligomer_3 to prepare the corresponding networks named PULCN(AZO)_1, PULCN(AZO)_2, and PULCN(AZO)_3, of which gel contents were determined to be $80.1 \%, 82.7 \%$, and $86.5 \%$, respectively. The relatively high degree of crosslinking should inherently limit the orientation of LC mesogens as well as the ability of the network to rearrange in the absence of a dynamic urethane bond.

In an earlier study [28], we found that because the polymer chain was rigid, the liquid crystal network (LCN) was brittle at room temperature. Herein, we used the soft part of ${ }^{4} \mathrm{PEG}_{4 \mathrm{k}}$ to connect the rigid chain contained in the LC mesogens and make the resultant film more flexible and have better mechanical properties. As an example, a typical stress-stain test was done on the PULCN(AZO)_1 film and the control sample (PULCN(AZO)_1_control) as shown in Fig. S2. Although the tensile strength $(\sigma)$ decreases slightly from 12.6 to $9.0 \mathrm{MPa}$, the elongation at break $(\varepsilon)$ increases 13 times from $15 \%$ to $201 \%$.

\section{Thermal behaviors of PULCN(AZO)s}

To investigate the thermo-activated SME in this system, DSC was employed to elucidate the transition temperatures $\left(T_{\text {trans }}\right)$ of PULCN(AZO)s. The DSC curves of PULCN(AZO)s are shown in Fig. 2, and the relevant values are detailed in Table 1 . In the first cooling scan (Fig. 2a), three distinct thermal transitions assigned to crystallization temperature $\left(T_{\mathrm{c}}\right), T_{\mathrm{g}}$, and $T_{\mathrm{cl}}$ were detected in all samples. The crystalline PEG has clearly been affected by the LC chain. With a shorter LC oligomer backbone, the $T_{\mathrm{c}}$ of PEG increased from -9.8 to $-0.7^{\circ} \mathrm{C}$ while its enthalpy had a corresponding uptrend. The $T_{\mathrm{cl}}$ of PULCN(AZO)s was kept almost constant at $\sim 79.5$ and $\sim 85.0^{\circ} \mathrm{C}$ during the cooling and heating run, respectively. However, the relevant enthalpy values varied significantly from 4.8 to $1.0 \mathrm{~J} \mathrm{~g}^{-1}$, depending on the LC oligomer length. In the second heating curve (Fig. $2 \mathrm{~b}$ ), the $T_{\mathrm{g}}$ of the LC chain and $T_{\mathrm{m}}$ of the PEG segment completely overlapped. These two transitions could be utilized as one $T_{\text {trans }}$ to cause shape change. The DSC results reveal that two independent $T_{\text {trans }}$ can potentially induce a TSME.
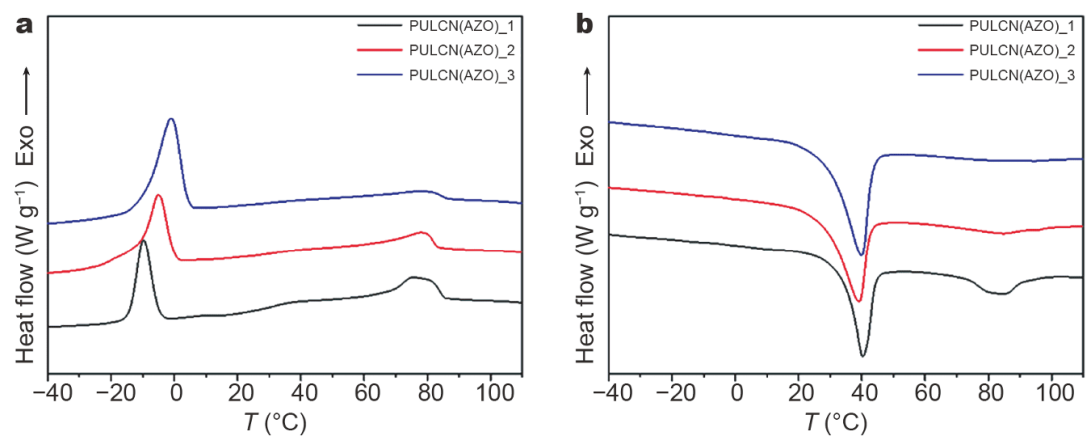

Figure 2 DSC curves of PULCN(AZO)s with a rate of $\pm 10{ }^{\circ} \mathrm{C} \min ^{-1}$ : (a) first cooling scan (b) second heating scan.

Table 1 The relevant values of PULCN(AZO)s determined by DSC

\begin{tabular}{cccccccccc}
\hline Samples & $T_{\mathrm{g}}\left({ }^{\circ} \mathrm{C}\right)$ & $T_{\mathrm{cl}}{ }^{\mathrm{a}}\left({ }^{\circ} \mathrm{C}\right)$ & $\Delta H_{\mathrm{cl}}{ }^{\mathrm{a}}\left(\mathrm{J} \mathrm{g}^{-1}\right)$ & $T_{\mathrm{cl}}{ }^{\mathrm{b}}\left({ }^{\circ} \mathrm{C}\right)$ & $\Delta H_{\mathrm{cl}}{ }^{\mathrm{b}}\left(\mathrm{J} \mathrm{g}^{-1}\right)$ & $T_{\mathrm{m}}\left({ }^{\circ} \mathrm{C}\right)$ & $\Delta H_{\mathrm{m}}\left(\mathrm{J} \mathrm{g}^{-1}\right)$ & $T_{\mathrm{c}}\left({ }^{\circ} \mathrm{C}\right)$ & $\Delta H_{\mathrm{c}}\left(\mathrm{J} \mathrm{g}^{-1}\right)$ \\
\hline PULCN(AZO)_1 & 31.5 & 85.1 & 4.7 & 79.5 & 4.8 & 40.3 & 19.1 & -9.8 & 15.4 \\
PULCN(AZO)_2 & 31.0 & 84.5 & 0.7 & 79.3 & 2.3 & 39.1 & 25.01 & -5.0 & 18.3 \\
PULCN(AZO)_3 & 30.7 & - & - & 79.4 & 1.0 & 39.9 & 30.5 & -0.9 & 25.4 \\
\hline
\end{tabular}

$T_{\mathrm{cl}}{ }^{\mathrm{a}}$ and $\Delta H_{\mathrm{cl}}{ }^{\mathrm{a}}$ : the phase transition temperature and the relevant enthalpy from LC phase to isotropic phase during heating, respectively. $T_{\mathrm{cl}}{ }^{\mathrm{b}}$ and $\Delta H_{\mathrm{cl}}^{\mathrm{b}}$ : the phase transition temperature and the relevant enthalpy from isotropic phase to LC phase during cooling, respectively. $\Delta H_{\mathrm{m}}$ : the melting enthalpy. $\Delta H_{c}$ : the crystallization enthalpy. 
The storage modulus-temperature curves of PULCN (AZO)s are shown in the Fig. 3. Based on the DSC results, the $T_{\mathrm{g}}$ of the LC chain and $T_{\mathrm{m}}$ of PEG overlap at $30-40^{\circ} \mathrm{C}$; the first drop at $\sim 65^{\circ} \mathrm{C}$ is assigned to these transition temperatures (identified as $T_{\text {trans_1 } 1}$ ). When the temperature was below $T_{\text {trans_1 }}$, crosslinked density increased with an increase in the flexible portion of the network. At the same time, the rigid LC backbone shortened. The competition results in a downtrend of the storage modulus $\left(E^{\prime}\right)$ with a shorter chain oligomer. As the temperature got close to $T_{\text {trans_l }}$, the $E^{\prime}$ decreased dramatically with a broad characteristic peak observed on the $\tan \delta$ curve. A second drop in $E^{\prime}$, caused by LC-isotropic phase transition $\left(T_{\mathrm{cl}}\right)$, was detected at approximately $110^{\circ} \mathrm{C}$. As expected, two independent $T_{\text {trans }}$ were observed using DMA.

\section{Microstructural analysis}

To determine the microstructure of the materials as well as their performance in SME, a stretched PULCN(AZO) _1 film was prepared using a DMA Q800 system in a controlled force mode. The polymer chain was first aligned along the stretching direction under external stress. The LC phase was observed on cooling from the isotropic phase to $65^{\circ} \mathrm{C}$ (Fig. 4). The POM view is bright when the sample is parallel to the analyzer (Fig. 4a left), but changes to dark under a small tilted angle (Fig. 4a right). The POM result reveals a smectic $\mathrm{C}(\mathrm{SmC})$ phase because the orientation of LC mesogens is not along the stretching direction. Moreover, a strong anisotropy was detected in the X-ray scattering patterns on the same stretched film (Fig. 4b). The four-spot patterns obtained in the small angle region at $65^{\circ} \mathrm{C}$ show that the layer normal direction is tilted away from the molecular long axis, which is a typical feature of SmC. Further, the same result was obtained on a relaxation film because the polymer chain maintained the same direction before and

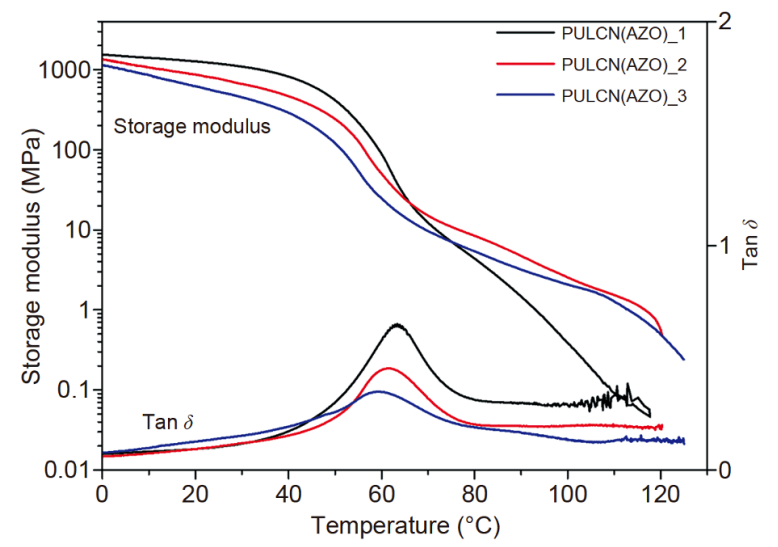

Figure 3 Storage modulus-temperature curves of PULCN(AZO)s.

after stress relaxation.

\section{Triple shape memory effect}

Two independent $T_{\text {trans }}\left(T_{\text {trans }}=T_{\mathrm{g}}+T_{\mathrm{m}}\right.$ and $\left.T_{\mathrm{cl}}\right)$ confirmed in previous analyses were employed to actuate TSME. Three programing temperatures, 0,65 and $105^{\circ} \mathrm{C}$ were selected for the thermomechanical and microstructural analyses. The detailed testing procedures and calculation are described in the Supplementary information. Fig. 5a illustrates the typical TSME of PULCN(AZO) _ 1 detected using DMA in a force-controlled mode. Digital pictures show the programming of temporary shapes $\left(S_{1}\right.$ and $\left.S_{2}\right)$ from the original shape $\left(S_{0}\right)$ and the stepwise recovery with thermal stimuli (Fig. 5b). The average fixity ratio $\left(R_{\mathrm{f}}\right)$ and recovery ratio $\left(R_{\mathrm{r}}\right)$ of all samples were calculated from 2-4 cycles and summarized in Table 2 . As expected, the performance was highly dependent on the architecture of these networks (Fig. S3). Shape $S_{1}$ was driven by $T_{\mathrm{c}}$. The temporary shape was fixed by $\mathrm{SmC}$ formation from the isotropic phase. With a shortened LC oligomer backbone, the enthalpy values of LC phase
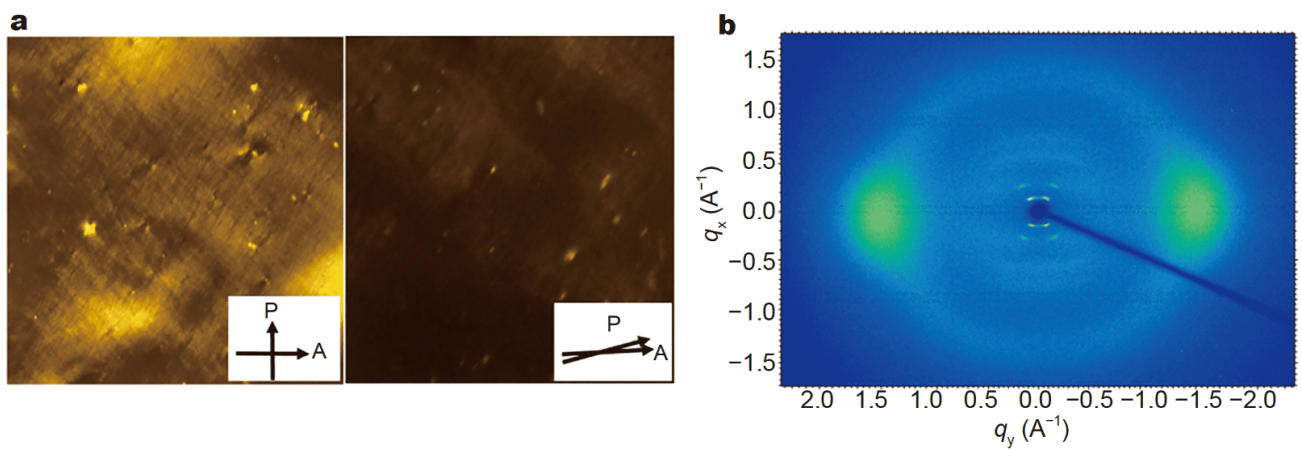

Figure 4 Microstructure of the stretched PULCN(AZO)_1. (a) Liquid crystalline textures recorded by POM at $65^{\circ} \mathrm{C}$; thickness: 20 $\mu \mathrm{m}$; (b) $2 \mathrm{D}$ WAXD images at $65^{\circ} \mathrm{C}$. 

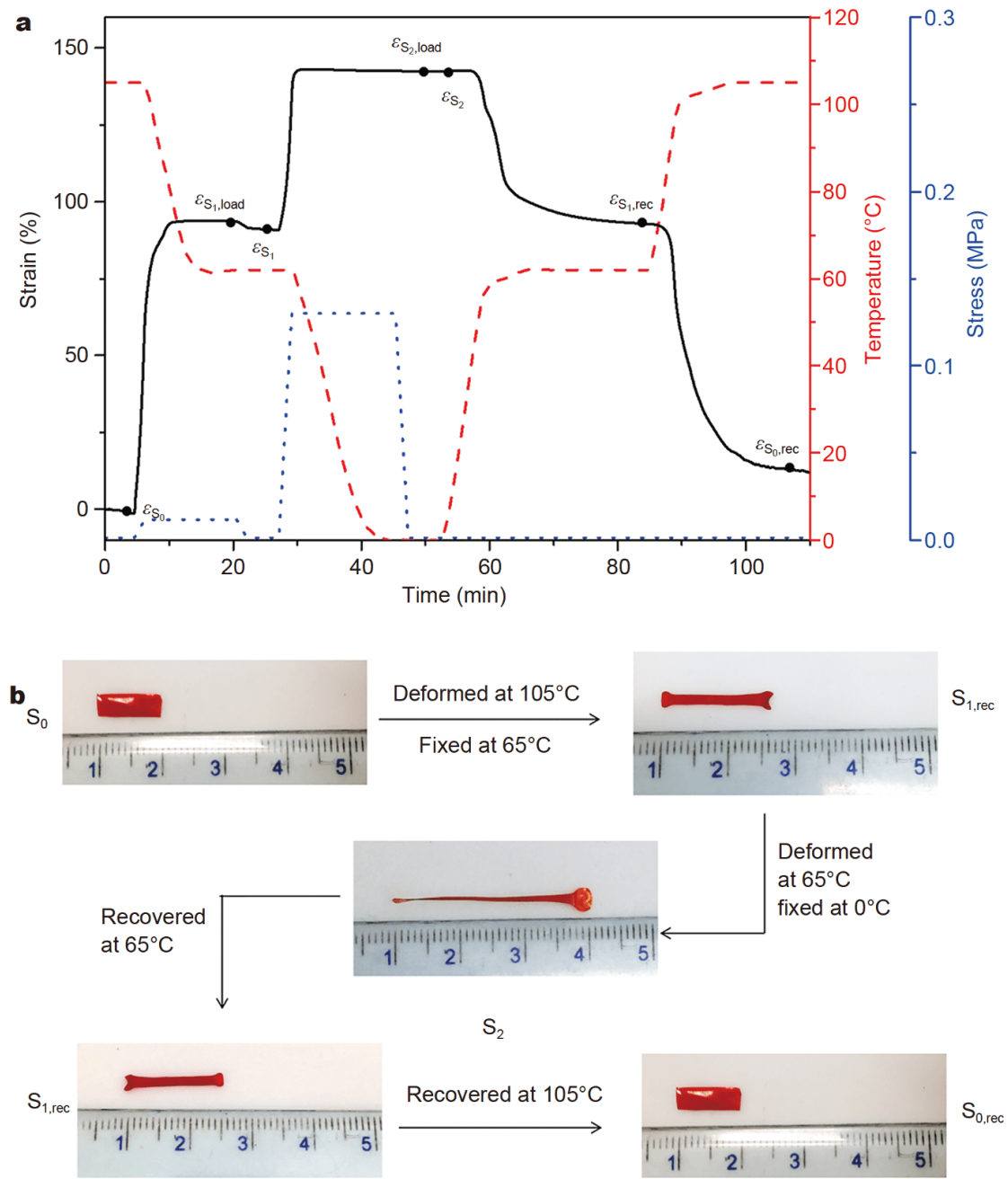

Figure 5 TSME of PULCN(AZO)_1. (a) Cyclic thermal mechanical test recorded by DMA. (b) Digital photos show a TSME cycle.

transition decreased as expected and the $R_{\mathrm{f}}\left(\mathrm{S}_{0} \rightarrow \mathrm{S}_{1}\right)$ reduced from $97.1 \%$ to $65.9 \%$. On the other hand, the relevant $R_{\mathrm{r}}\left(\mathrm{S}_{1} \rightarrow \mathrm{S}_{0}\right)$ ranged between $88.2 \%$ and $102.8 \%$ as the crosslinking densities increased. Shape $S_{2}$, determined by synergism of $T_{\mathrm{g}}$ of the LC chain and $T_{\mathrm{m}}$ of PEG, has an outstanding $R_{\mathrm{f}}\left(\mathrm{S}_{1} \rightarrow \mathrm{S}_{2}\right)$ of over $95 \%$ as well as a high $R_{\mathrm{r}}$ $\left(\mathrm{S}_{2} \rightarrow \mathrm{S}_{1}\right)$ of above $92 \%$. Interestingly, PULCN(AZO)_1 has the best $R_{\mathrm{f}}\left(\mathrm{S}_{1} \rightarrow \mathrm{S}_{2}\right)$ and $R_{\mathrm{r}}\left(\mathrm{S}_{2} \rightarrow \mathrm{S}_{1}\right)$, revealing that the LC backbone plays a major role in this process. As a result, TSME was achieved in the materials with an excellent total $R_{\mathrm{r}}\left(\mathrm{S}_{2} \rightarrow \mathrm{S}_{0}\right)$ ranging from $91.0 \%$ to $97.0 \%$.

\section{Coupling thermo- and photo-responsive two-way free- standing actuation}

A uniform monodomain film is a precondition for achieving an autonomous actuator. This work presents a robust and straightforward method to program, on a large size and scale, LCNs with uniform alignment. The

Table 2 Triple shape memory properties of PULCN(AZO)s recorded from cyclic thermomechanical tests

\begin{tabular}{|c|c|c|c|c|c|}
\hline \multirow{2}{*}{ Samples } & \multicolumn{2}{|c|}{$R_{\mathrm{f}}$} & \multicolumn{3}{|c|}{$R_{\mathrm{r}}$} \\
\hline & $\mathrm{S}_{0} \rightarrow \mathrm{S}_{1}$ & $\mathrm{~S}_{1} \rightarrow \mathrm{S}_{2}$ & $\mathrm{~S}_{2} \rightarrow \mathrm{S}_{1}$ & $\mathrm{~S}_{1} \rightarrow \mathrm{S}_{0}$ & $\mathrm{~S}_{2} \rightarrow \mathrm{S}_{0}$ \\
\hline PULCN(AZO)_1 & $97.1 \pm 0.0$ & $99.8 \pm 0.0$ & $96.3 \pm 0.4$ & $88.2 \pm 0.2$ & $91.0 \pm 0.3$ \\
\hline PULCN(AZO)_2 & $82.7 \pm 0.1$ & $98.9 \pm 0.2$ & $92.4 \pm 1.8$ & $101.0 \pm 3.8$ & $96.7 \pm 3.0$ \\
\hline PULCN(AZO)_3 & $65.9 \pm 3.4$ & $95.0 \pm 0.4$ & $92.0 \pm 2.2$ & $102.8 \pm 1.6$ & $97.0 \pm 0.6$ \\
\hline
\end{tabular}


sample was prepared after complete stress relaxation via bond exchange of a carbamate group (Fig. 6a). The programmed polymer chain was orientated along the axis of applied constant strain to align the LC mesogens. Twoway thermo- and photo-induced reversible actuations were carried out on a monodomain film by reprogramming the topology of the chemical network (Fig. 1b, c). In a thermal cycle, a completely reversible free-standing actuation of up to $\sim 70 \%$ was detected by DMA. The temporary shape was reserved by forming an LC phase and returned to its initial state upon heating to the isotropic phase (Fig. 6b).

Moreover, a fully reversible trans-cis photoisomerization of azobenzene introduced by visible light (450 and $550 \mathrm{~nm}$ ) was investigated. The UV-Vis absorption peak of $\pi-\pi^{*}$ transition of the trans isomer at $435 \mathrm{~nm}$ dramatically decreased upon irradiation with $450 \mathrm{~nm}$ visible light, while the characteristic peak at $550 \mathrm{~nm}$ assigned to the $\mathrm{n}$ $\pi^{*}$ transition of the cis isomer increased within $30 \mathrm{~s}$ (Fig. 6c). As expected, the induced cis isomer went back to the stable trans state upon exposure to $550 \mathrm{~nm}$ light (Fig. 6d). After the LC-isotropic phase transition and trans-cis photoisomerization of azobenzene, the reversible thermo-induced contraction/extension actuation and photo-induced bending/unbending behaviors were car- ried out on the aligned PULCN(AZO)_1 film shown in Fig. 1d. Digital photos show the programmed monodomain film elongated from 1.4 to $2.3 \mathrm{~cm}$ when cooled to the LC phase. Further, when the sample was exposed to $450 \mathrm{~nm}$ visible light in the LC state at $65^{\circ} \mathrm{C}$, the order parameter in the surface decreased due to the transfer of rod-like trans mesogens to bent cis isomers, causing the film to bend toward the light gradually. The bent film returned to a flat shape and its initial 1.4-cm length under stepwise photo and heat stimuli or when directly heated to the isotropic state. In addition, the temporary shapes can be kept for a long time because of the frozen polymer chain and the crystallinity of PEG. Coupling the thermoand photo-induced free-standing actuation of the polymer network has potential applications in emerging multifunctional devices.

\section{CONCLUSIONS}

In summary, we prepared thermo- and photo-responsive shape memory PULCN(AZO)s. These polymeric networks were synthesized from AZO-diol and HDI, followed by crosslinking with ${ }^{4} \mathrm{PEG}_{4 \mathrm{k}}$. A uniform monodomain was prepared by dynamic bond exchange of the carbamate functional group. Using two independent $T_{\text {trans }}$, thermal TSME were demonstrated. The perfor-
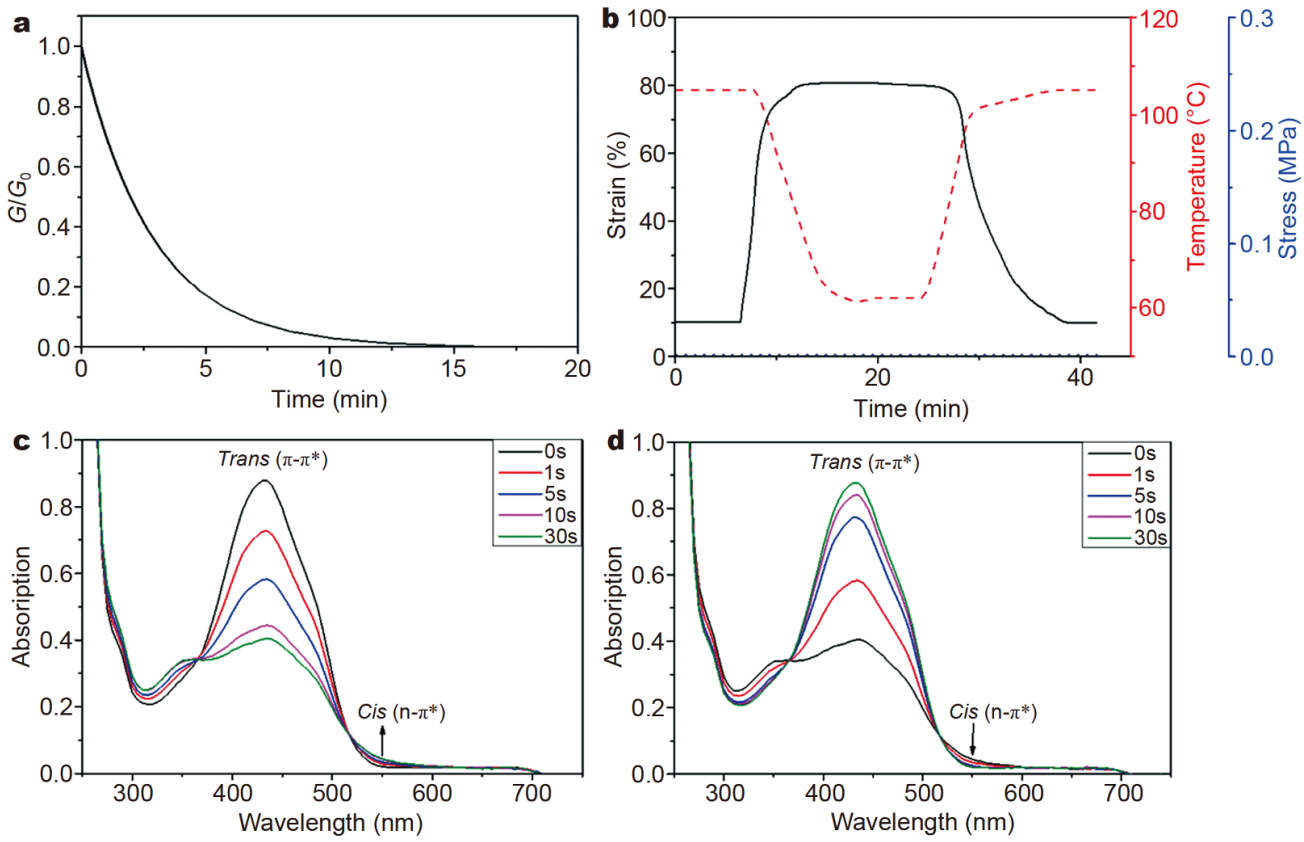

Figure 6 (a) Thermal stress relaxation in the PULCN(AZO)_1 film at $150^{\circ} \mathrm{C}$ for 30 min with a stain of $10 \%$. Catalyst: DBTDL (1 mol\%). G and $G_{0}$ represent the instantaneous and the initial relaxation modulus, respectively. (b) Two-way free-standing SME on monodomain PULCN(AZO)_1 following stress relaxation-based programming (pre-stretched strain: $10 \%$; temperature: $150^{\circ} \mathrm{C}$ ). (c) The UV-Vis absorption spectra of oligomer_1 in DMSO solution at room temperature upon irradiation with $450 \mathrm{~nm}$ visible light. (d) The UV-Vis absorption spectra of oligomer_1 in DMSO solution at room temperature upon irradiation with $550 \mathrm{~nm}$ visible light. 
mance was clearly affected by the LC oligomer backbone with $R_{\mathrm{f}}\left(\mathrm{S}_{0} \rightarrow \mathrm{S}_{1}\right)$ ranging from $97.1 \%$ to $65.9 \%$ because of the natural formation of the $\mathrm{SmC}$ phase from the isotropic phase. The total recovery ratios were improved since $R_{\mathrm{r}}\left(\mathrm{S}_{2} \rightarrow \mathrm{S}_{0}\right)$ went from $91.0 \%$ to $97.0 \%$. Coupling the autonomously thermo-induced contraction/extension actuation (LC-isotropic phase transition) and reversible photo-induced bending/unbending behaviors was achieved in one aligned film. Additionally, a temporary shape can be designed and frozen in an expected state. This phenomenon is of significance in smart devices.

\section{Received 7 April 2020; accepted 20 May 2020;} published online 21 July 2020

1 Warner M, Terentjev EM. Liquid crystal elastomers. Oxford: Oxford University Press, 2007

2 Ohm C, Brehmer M, Zentel R. Liquid crystalline elastomers as actuators and sensors. Adv Mater, 2010, 22: 3366-3387

3 White TJ, Broer DJ. Programmable and adaptive mechanics with liquid crystal polymer networks and elastomers. Nat Mater, 2015, 14: 1087-1098

4 Ge F, Zhao Y. Microstructured actuation of liquid crystal polymer networks. Adv Funct Mater, 2020, 30: 1901890-1901909

5 Wen ZB, Yang KK, Raquez JM. A review on liquid crystal polymers in free-standing reversible shape memory materials. Molecules, 2020, 25: 1241-1254

6 Li MH, Keller P. Artificial muscles based on liquid crystal elastomers. Philos Trans R Soc A-Math Phys Eng Sci, 2006, 364: $2763-$ 2777

7 Zhan Y, Schenning APHJ, Broer DJ, et al. Light-driven electrohydrodynamic instabilities in liquid crystals. Adv Funct Mater, 2018, 28: 1707436

8 Liu D, Bastiaansen CWM, den Toonder JMJ, et al. Photo-switchable surface topologies in chiral nematic coatings. Angew Chem Int Ed, 2012, 51: 892-896

9 Maria LV, Liu DQ, Broer DJ, et al. 4D printed actuators with softrobotic functions. Macromol Rapid Commun, 2018, 39: 17007101700717

10 Li MH, Keller P, Li B, et al. Light-driven side-on nematic elastomer actuators. Adv Mater, 2003, 15: 569-572

11 Buguin A, Li MH, Silberzan P, et al. Micro-actuators: When artificial muscles made of nematic liquid crystal elastomers meet soft lithography. J Am Chem Soc, 2006, 128: 1088-1089

12 Yang H, Buguin A, Taulemesse JM, et al. Micron-sized main-chain liquid crystalline elastomer actuators with ultralarge amplitude contractions. J Am Chem Soc, 2009, 131: 15000-15004

13 Ohm C, Serra C, Zentel R. A continuous flow synthesis of micrometer-sized actuators from liquid crystalline elastomers. Adv Mater, 2009, 21: 4859-4862

14 Krause S, Zander F, Bergmann G, et al. Nematic main-chain elastomers: Coupling and orientational behavior. Comptes Rendus Chimie, 2009, 12: 85-104

15 Chen Q, Wei Y, Ji Y. Photo-responsive liquid crystalline vitrimer containing oligoanilines. Chin Chem Lett, 2017, 28: 2139-2142

16 Ahir SV, Terentjev EM. Photomechanical actuation in polymernanotube composites. Nat Mater, 2005, 4: 491-495

17 Yu Y, Nakano M, Ikeda T. Directed bending of a polymer film by light. Nature, 2003, 425: 145

18 Lee KM, Koerner H, Vaia RA, et al. Light-activated shape memory of glassy, azobenzene liquid crystalline polymer networks. Soft Matter, 2011, 7: 4318-4324

19 Zhong HY, Chen L, Ding XM, et al. Physio- and chemo-dual crosslinking toward thermo and photo-response of azobenzenecontaining liquid crystalline polyester. Sci China Mater, 2018, 61: $1225-1236$

20 Wie JJ, Shankar MR, White TJ. Photomotility of polymers. Nat Commun, 2016, 7: 13260-13268

21 Serak S, Tabiryan N, Vergara R, et al. Liquid crystalline polymer cantilever oscillators fueled by light. Soft Matter, 2010, 6: 779-783

22 Liu Y, Xu B, Sun S, et al. Humidity- and photo-induced mechanical actuation of cross-linked liquid crystal polymers. Adv Mater, 2017, 29: 1604792

23 Yamada M, Kondo M, Mamiya J, et al. Photomobile polymer materials: Towards light-driven plastic motors. Angew Chem Int Ed, 2008, 47: 4986-4988

24 Jiang Z, Xu M, Li F, et al. Red-light-controllable liquid-crystal soft actuators via low-power excited ppconversion based on triplettriplet annihilation. J Am Chem Soc, 2013, 135: 16446-16453

25 Lv J, Liu Y, Wei J, et al. Photocontrol of fluid slugs in liquid crystal polymer microactuators. Nature, 2016, 537: 179-184

26 Kumar K, Knie C, Bléger D, et al. A chaotic self-oscillating sunlight-driven polymer actuator. Nat Commun, 2016, 7: 1197511983

27 Gelebart AH, Vantomme G, Meijer EW, et al. Mastering the photothermal effect in liquid crystal networks: A general approach for self-sustained mechanical oscillators. Adv Mater, 2017, 29: 1606712-1606718

28 Wen ZB, Liu D, Li XY, et al. Fabrication of liquid crystalline polyurethane networks with a pendant azobenzene group to access thermal/photoresponsive shape-memory effects. ACS Appl Mater Interfaces, 2017, 9: 24947-24954

29 Küpfer J, Finkelmann H. Nematic liquid single crystal elastomers. Makromol Chem Rapid Commun, 1991, 12: 717-726

30 Tajbakhsh AR, Terentjev EM. Spontaneous thermal expansion of nematic elastomers. Eur Phys J E, 2001, 6: 181-188

31 Yakacki CM, Saed M, Nair DP, et al. Tailorable and programmable liquid-crystalline elastomers using a two-stage thiol-acrylate reaction. RSC Adv, 2015, 5: 18997-19001

32 White TJ, Serak SV, Tabiryan NV, et al. Polarization-controlled, photodriven bending in monodomain liquid crystal elastomer cantilevers. J Mater Chem, 2009, 19: 1080-1085

33 Urayama K, Arai YO, Takigawa T. Volume phase transition of monodomain nematic polymer networks in isotropic solvents accompanied by anisotropic shape variation. Macromolecules, 2005, 38: 3469-3474

34 Ichimura K. Photoalignment of liquid-crystal systems. Chem Rev, 2000, 100: 1847-1874

35 Zeng H, Wani OM, Wasylczyk $\mathrm{P}$, et al. Self-regulating iris based on light-actuated liquid crystal elastomer. Adv Mater, 2017, 29: 1701814-1701821

36 Gebhard E, Zentel R. Ferroelectric liquid crystalline elastomers. 2. Variation of mesogens and network density. Macromol Chem Phys, 2000, 201: 911-922

37 Krause S, Dersch R, Wendorff JH, et al. Photocrosslinkable liquid crystal main-chain polymers: thin films and electrospinning. Macromol Rapid Commun, 2007, 28: 2062-2068

38 Minemawari $\mathrm{H}$, Yamada $\mathrm{T}$, Matsui $\mathrm{H}$, et al. Inkjet printing of 
single-crystal films. Nature, 2011, 475: 364-367

39 van Oosten CL, Bastiaansen CWM, Broer DJ. Printed artificial cilia from liquid-crystal network actuators modularly driven by light. Nat Mater, 2009, 8: 677-682

40 Kotikian A, Truby RL, Boley JW, et al. 3D printing of liquid crystal elastomeric actuators with spatially programed nematic order. Adv Mater, 2018, 30: 1706164-1706170

$41 \mathrm{Wu} J$ J, Huang LM, Zhao Q, et al. 4D printing: History and recent progress. Chin J Polym Sci, 2018, 36: 563-575

42 Yang Z, Herd GA, Clarke SM, et al. Thermal and UV shape shifting of surface topography. J Am Chem Soc, 2006, 128: 10741075

43 Yang H, Ye G, Wang X, et al. Micron-sized liquid crystalline elastomer actuators. Soft Matter, 2011, 7: 815-823

44 Montarnal D, Capelot M, Tournilhac F, et al. Silica-like malleable materials from permanent organic networks. Science, 2011, 334: 965-968

45 Kloxin CJ, Bowman CN. Covalent adaptable networks: Smart, reconfigurable and responsive network systems. Chem Soc Rev, 2013, 42: 7161-7173

46 Chen QM, Yang Y, Wei Y, et al. Liquid crystalline polymer actuators with exchangeable dynamic covalent bonds. Acta Polym Sin, 2019, 5: 451-468

47 Lu X, Zhang H, Fei G, et al. Liquid-crystalline dynamic networks doped with gold nanorods showing enhanced photocontrol of actuation. Adv Mater, 2018, 30: e1706597

48 Chen Q, Li Y, Yang Y, et al. Durable liquid-crystalline vitrimer actuators. Chem Sci, 2019, 10: 3025-3030

49 Pei Z, Yang Y, Chen Q, et al. Mouldable liquid-crystalline elastomer actuators with exchangeable covalent bonds. Nat Mater, 2014, 13: $36-41$

50 Wen ZB, McBride MK, Zhang XP, et al. Reconfigurable LC elastomers: Using a thermally programmable monodomain to access two-way free-standing multiple shape memory polymers. Macromolecules, 2018, 51: 5812-5819

51 Saed MO, Gablier A, Terentejv EM. Liquid crystalline vitrimers with full or partial boronic-ester bond exchange. Adv Funct Mater, 2020, 30: 1906458-1906466

52 Wang Z, He Q, Wang Y, et al. Programmable actuation of liquid crystal elastomers via "living" exchange reaction. Soft Matter, 2019, 15: $2811-2816$

53 Deng XY, Xie H, Du L, et al. Polyurethane networks based on disulfide bonds: From tunable multi-shape memory effects to simultaneous self-healing. Sci China Mater, 2019, 62: 437-447

54 McBride MK, Hendrikx M, Liu D, et al. Photoinduced plasticity in cross-linked liquid crystalline networks. Adv Mater, 2017, 29: 1606509-1606515

55 McBride MK, Martinez AM, Cox L, et al. A readily programmable, fully reversible shape-switching material. Sci Adv, 2018, 4: eaat 4634

56 Davidson EC, Kotikian A, Li S, et al. 3D printable and reconfigurable liquid crystal elastomers with light-induced shape memory via dynamic bond exchange. Adv Mater, 2020, 32: 1905682-1905688

57 Wen ZB, Zhang TH, Hui Y, et al. Elaborate fabrication of welldefined side-chain liquid crystalline polyurethane networks with triple-shape memory capacity. J Mater Chem A, 2015, 3: 1343513444

Acknowledgements Wen ZB gratefully acknowledges the use of fa- cilities and instrumentation supported by the National Science Foundation of Materials Research Science and Engineering Centers Grant (DMR-1420736, University of Colorado, Boulder). This work was supported financially by the National Natural Science Foundation of China (51773131 and 51721091) and the Fundamental Research Funds for the Central Universities.

Author contributions Wen $\mathrm{ZB}$ designed the structure, performed the experiments, analyzed the data and wrote the draft of manuscript with support from Yang KK; Yang KK and Wang YZ proposed the project and gave critical comments of the manuscript; Snap RF and Clark NA analyzed the experimental results of POM and WAXD; Raquez JM checked and approved the manuscript. All authors contributed to the general discussion.

Conflict of interest The authors declare that they have no conflict of interest.

Supplementary information Experimental details and supporting data are available in the online version of the paper.

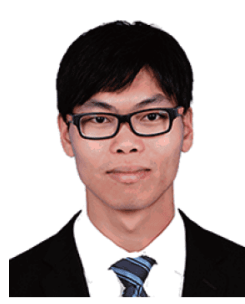

Zhi-Bin Wen received his $\mathrm{PhD}$ degree in polymer chemistry and physics from Sichuan University in 2018. He currently does his postdoctoral research at the University of Mons. His research focuses on shape-memory polymers, liquid crystal materials and covalent adaptable networks.

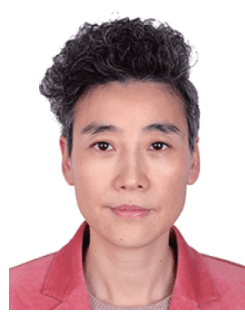

Ke-Ke Yang received her BSc degree in polymer materials (1994), MSc degree in chemical fiber (1997), and PhD degree in material science from Sichuan University in China. She joined Sichuan University in 1997, and now is a full professor in polymer chemistry and physics. Her research focuses on biodegradable polymers, polymer composites, shape-memory polymers and selfhealing materials.

\section{优异的无应力双向光热响应形状记忆偶氮液晶聚 氨酯网络}

文志斌, 1,2, Ren-Fan Shao ${ }^{2}$, Jean-Marie Raquez ${ }^{3}$, Noel A. Clark ${ }^{2}$, 杨科珂 ${ }^{*}$, 王玉忠

摘要 本文以羟基修饰偶氮液晶小分子为单体、异氰酸酯为扩链 剂、四臂聚乙二醇为交联剂一锅法合成了一系列液晶聚氨酯网络 (PULCN (AZO)s), 并通过调节反应原料的投料比精确控制网络结 构. 该交联网络呈现两个独立的热转变温度 $\left(T_{\text {trans }}\right)$, 以此为驱动温 度可实现热致三重形状记忆效应. 进一步利用氨酷键在高温下的 动态热交换获得单畴化液晶交联网络, 该交联网络不仅可呈现热 致无应力双向形状记忆效应, 同时利用偶氮苯光致异构转变特性, 还可以在 450 和 $550 \mathrm{~nm}$ 可见光的照射下分别展示出弯曲与回复的 光致形变能力. 将光、热响应的无应力可逆形变结合在单一循环 中, 可实现材料在多个形状之间的可逆变化. 该材料有望应用于多 功能设备中. 